\title{
Cork: New uses in Architecture
}

\section{SIGRADI2018 TECHNOPOLITICAS xxii congresso da sociedade iberoamericana de gráfica digital 22th conference of the iberoamerican society of digital graphics 07|08|09|novembro|2018 iau usp | são carlos | sp br}

\author{
Cristina Verissimo \\ Dalhousie University | Canada | cristina.verissimo@dal.ca
}

\begin{abstract}
Cork usage is one of the most promising trends in sustainable development of materials, due to its unique natural properties, exceptionally good environmental qualities and its high potential to incorporate innovative technology. It can be reused, and it is built with renewable and reusable materials that contain lower levels of embedded energy and carbon. Today amongst other uses we see cork used as a textile for clothing, in automobile parts, and as a thermal shield in space crafts. However, there is still a lack of information and diffusion within the engineering and architecture sectors; stakeholders lack awareness of how to use and select cork materials for construction, compared with other competing products.
\end{abstract}

This research plans to explore future cork industry developments, cork recycling and new corkbased materials, which are still in various stages of development with enormous potential for construction as an eco-friendly solution. The aim is to test or adapt them to be used in construction, with an emphasis in CAD/CAM fabrication processes. Hoping that in the future there will be greater application in architecture and eventually will contribute to greater sustainability in the construction business as well as the cork sector.

Keywords: Cork; Sustainable material; Materials engineers design; Architecture; Culture.

\section{INTRODUCTION}

This research will create greater awareness of the potentialities of cork as a sustainable material and seek possible new uses of cork materials in architecture. Cork is a natural, recyclable, renewable and non-toxic resource, with a strong impact in Mediterranean culture and ecosystems for centuries. Recent developments in cork research demonstrate that its application goes far beyond the classical cork-wine cultural relationship that is globally recognized.

Developments in computational design methods and their integration with digital fabrication processes allows us to foresee that a file-to-factory digital process (Varela, Paio, \& Sousa, 2014) will have several advantages: higher quality and speed without sacrificing scope or increasing cost (Kieran \& Timberlake, 2003).

This paper is divided into three sections. First, it addresses the understandings of the qualities of cork material and its importance in the Mediterranean culture. Then defines the objectives of the research and the methodology are defined. Lastly, shows examples of the use of CAD-CAM methods to develop some prototypes.

\section{LANDSCAPE AND CULTURE}

Cork is a natural, recyclable and renewable material harvested from the living bark of the Cork Oak, Quercus Suber L. Though the Cork Oak can flourish in many climates, the conditions that favour commercial use lie in a fairly narrow swath that cuts through Western Europe and Northern Africa along the Mediterranean coast. Cork Oak forests are an agro-silvo-pastoral ecosystem, built by humans and preserved by control of shrubs and using natural resources (Potes, J. \& Babo, H. 2003).

Cork Oak trees are maintained through the persistence, hard work and passion of generations that through centuries planted the trees so their grandchildren could profit from the trees eventual harvesting.

This generational inheritance helped to reinforce and broaden the family links and values still, so common in the Mediterranean.

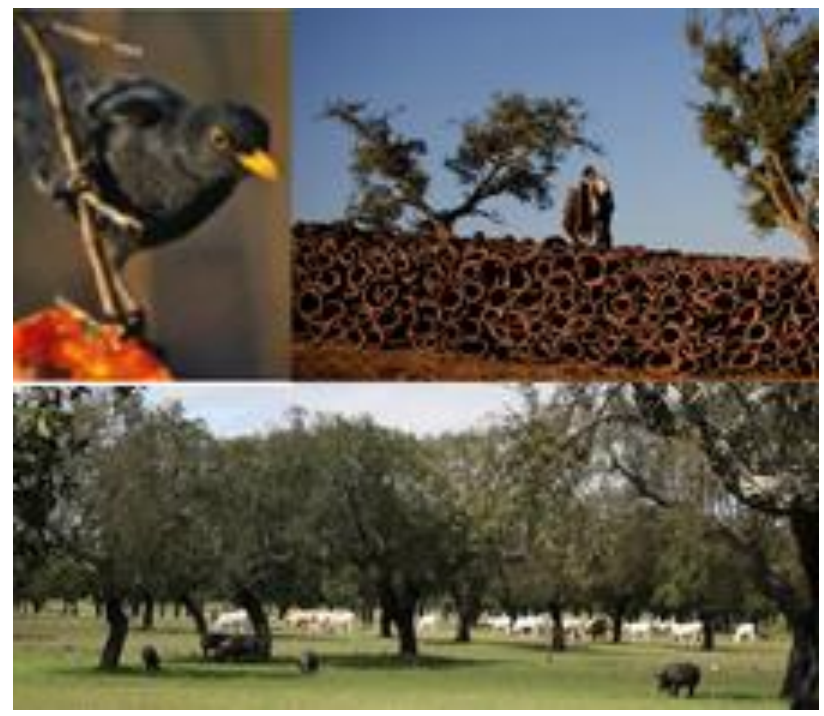

Figure 1: agro-silvo-pastoral ecosystem. Source: Author. 
The maintenance of the cork forests helps to prevent the advance of desertification, improve water penetration into the soil and hydrological regulation, and promote soil conservation, while being the perfect habitat for many flora and fauna species. Consequently, these forests promote biodiversity (Pereira, 2007; Gil, 2011).

A cork oak tree produces about four times more cork if it is harvested, with healthy growth benefits to the tree. It also increases the fixation of $\mathrm{CO} 2$ and enables the tree to flourish without the intervention of herbicides, fertilizers or irrigation. (Gil, 2010).

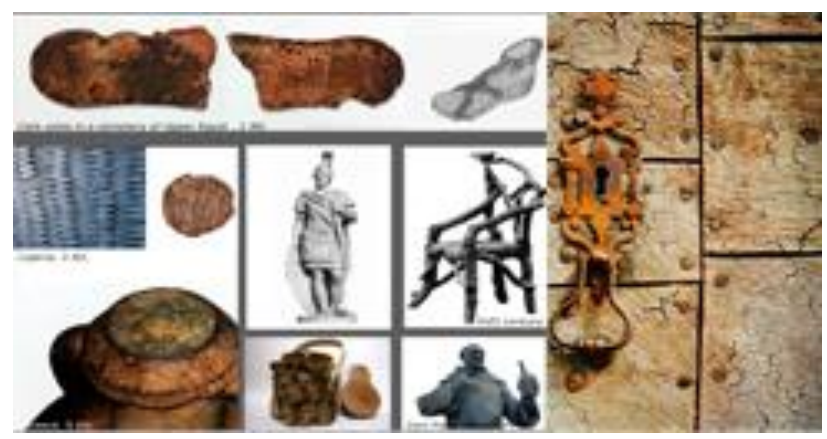

Figure 2: the use of cork through history. Source: Author.

\section{CORK AND HISTORY}

"Wine and cork were born and come together in the Mediterranean" (Santos, C. O. \& Amorim, A., 2008). The use of cork is ancient, especially along the Mediterranean with its use from daily life objects to architecture. Existing buildings, such as the Convent of the Capuchos of the XVI century, Sintra, Portugal, still show how cork was used as a finishing and outdoor material for comfort (Muchagato J.; Oliveira Martins A. 2013). Cork was an early product in a global market due to Portuguese and Spanish empires of the XVI century (Santos, C.O., 2000).

\section{CORK: A "SUPER MATERIAL"}

The unique properties of cork are derived from the structure and chemical composition of the inner cells. On average, there are approximately 40 million cells in each cubic centimeter of cork. Consequently, cork is very light, impermeable to liquids and gases, elastic and compressible, thermal effective, a sound insulator, resilient, high temperature resistant, fire retardant, hypoallergenic, shock absorbent, soft to the touch, and warm feeling. (Gil 2007). Cork is very versatile and adopts different technological transformation processes, giving rise to several products, which can be used in different applications. New demands for cork, give rise to new technologies, that can replace traditional methods, that expands the material's volume to three times larger than its original size, maintaining cork material qualities.

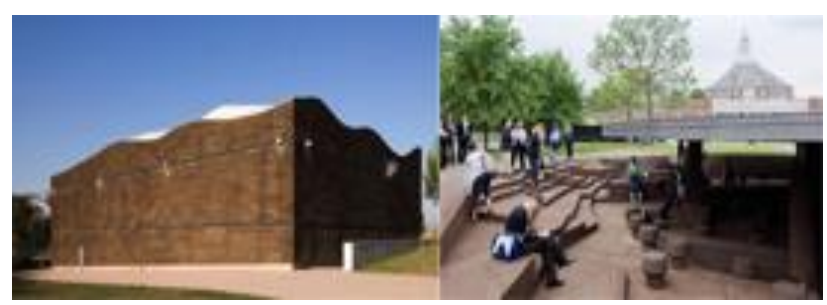

Figure 3: Alvaro Siza, Eduardo Souto de Moura, Portugal Pavilion for Hannover, Expo 2000 (left), Herzog \& DeMeuron and Ai Weiwei's cork Serpentine Gallery Pavilion 2012 (right). Source: Author.
Meanwhile, cork products for the construction industry are most suitable for sustainable and efficient energy construction, given the material's ecological characteristics. In addition, cork products contribute to general comfort and indoor air quality (Gil, 2007). This gives an opportunity in architecture for the use of cork as a primary material as in the past. In the last decade some examples of the use of cork notable are: the Portugal Pavilion for Expo 2000 Hannover exhibition, the Serpentine Pavilion, London, 2012 and the Portugal Pavilion Shanghai Expo 2010.

\section{RESEARCH AND METHODOLOGY}

This research began in July 2014, with the organization of an international workshop in Lisbon focused on the use of cork as a material in architecture. It provided an environment for researchers and architects, as well as those in the industry and other interested parties, to meet and develop ideas and experiments using cork. The Workshop is to be held annually (in July), proposing different challenges every year. In the future, it will be a platform for the internationalization of the use of cork as a building envelope material. It runs in a three-year cycle, organized by themes, according to the type of materials/prototypes that are going to be tested or developed during each workshop.

We used a CAD application to quickly experiment with different design solutions. One advantage of doing this is that we can save a lot of time in the generation of models. First, we have a fast visualizer, which generates a model almost instantaneously. Next, we frequently use three CAD applications, namely SketchUp, Rhino and AutoCAD, and finally we use ArchiCAD and Revit.

\section{WORKSHOP 1: NATURAL CORK}

For Workshop One: Year One, July 2014, the topic was the use of Natural Cork - Tradition. The objectives developed were: 1 - Gain an appreciation and understanding of Cork as a material. 2- Understanding traditional methods in the use of Cork and learn from that experience. 3 - Conducting explorations with natural cork or products using only natural cork, to understand its potentialities and possible applications as a building envelope. Extended research was conducted into recycling of residuals of natural cork produced by cork stopper manufacture. Since cork is a material with enormous potentialities of application, in order to reinforce the methodology, we divided the research into three main subjects for the workshops: cork as a membrane, cork as a finishing and cork as selfsupporting material. 


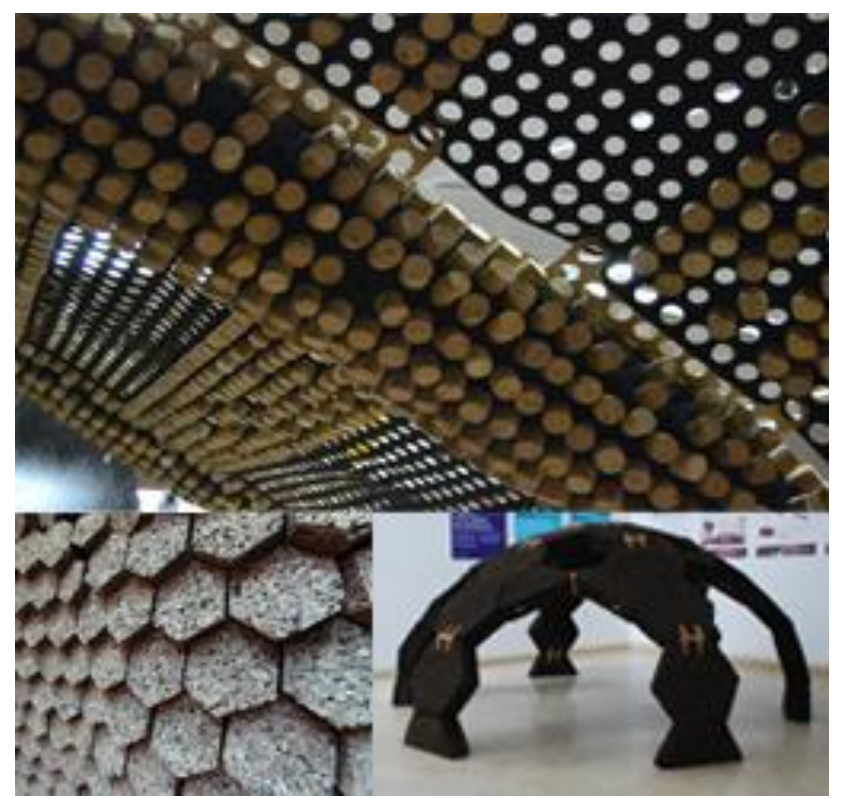

Figure 4: Cork used as a membrane (top). Cork used as a finishing material (left). Cork used as a self-supporting material (right). Source: Author.

These are three examples, of the over 20 experiences develop: In figure 4, cork is used as a membrane. The incorporation of recycled cork stoppers gives a surprising structure to the fabric and adds thermal insulation. The black agglomerated cork was transformed through CADCAM process into a tile that was applied as a finishing material to a curved surface, with thermal and acoustic benefits (left). On the right of figure 4 a dome was assembled using natural cork for joints and black agglomerated cork for the hexagon pieces. This dome can be folded and transported due to its lightweight.

\section{WORKSHOP 2: CORK COMPOSITE - INDUSTRY}

For Workshop Two: Year Two, July 2015, the topic was the use of Cork Composite - Industry. In the last decades there has been an important effort, from industry, to develop several new derivative products of cork, incorporating new technologies applied to traditional products. The objective of this research is to understand how some of these materials or products will be adapted for use in construction. Therefore, the research concentrated of: 1 knowing the industrial cork processing chain and the composite cork products. 2 - Selection and characterization of cork products and their use changes, i.e. with aging and weathering, with a selection of performance-related indicators. 3 - Conducting experiences in the Workshop involving the industry, overcoming potentialities of their materials. Extended research was conducted the recycling of residuals of composite cork produced by cork industry. It used the same methodology as in the previous year: cork as a membrane, cork as a finish and cork as a selfsupporting material.

These are three examples, of the over 20 experiences developed. In figure 5 (top), cork is used as a membrane. The double layer triangle pattern cork fabric was glued to natural fibers that work as a connecter element for the pattern. The interior of the triangles is filled with cork granules adding thermal insulation. As an alternative the triangles can be insufflate with air. In figure 5 (left), Rubber Cork Composite and Cork Resins, composite materials, made into a tile through CAD-CAM processes. A pattern

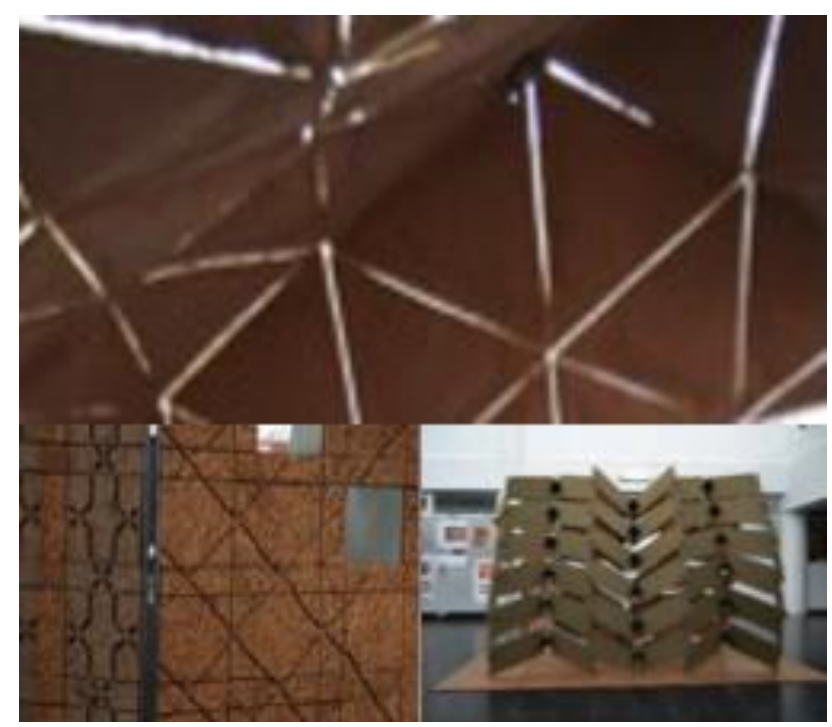

Figure 5: Cork used as a membrane (top). Cork used as a finishing material (left). Cork used as a self-supporting material (right). Source: Author.

was carved in the titles and flied with natural resin for transparency. The tiles were attached, as a finishing material, to a metal structure, with thermal and acoustic benefits. In figure 5 (right) a small pavilion was assembled using laminated wood and cork for surfaces and black rubber cork for joints. The pavilion was assembled without any metal joints.

\section{WORKSHOP 3: NEW MATERIALS - FUTURE TECHNOLOGIES}

For Workshop Three: Year Three, July 2016, the topic was New Materials - Future Technologies. In the last decades there has been an important awareness that architects have to start looking for natural and sustainable materials for building construction. Therefore, the research concentrated on: 1 - Understanding current architectural practices and foreseeing their future needs; 2 - Selection of new materials and technologies that can in the future bring new possibilities of use in architecture and product design; 3 - Understanding how research and industry can work together to develop strategic possibilities for future applications in architecture.

Considering the current industry, it was proposed to investigate the incorporation of CAD / CAM technologies at the end of the production line.

Different prototypes were developed using different manufacturing processes and design (material) topics. 


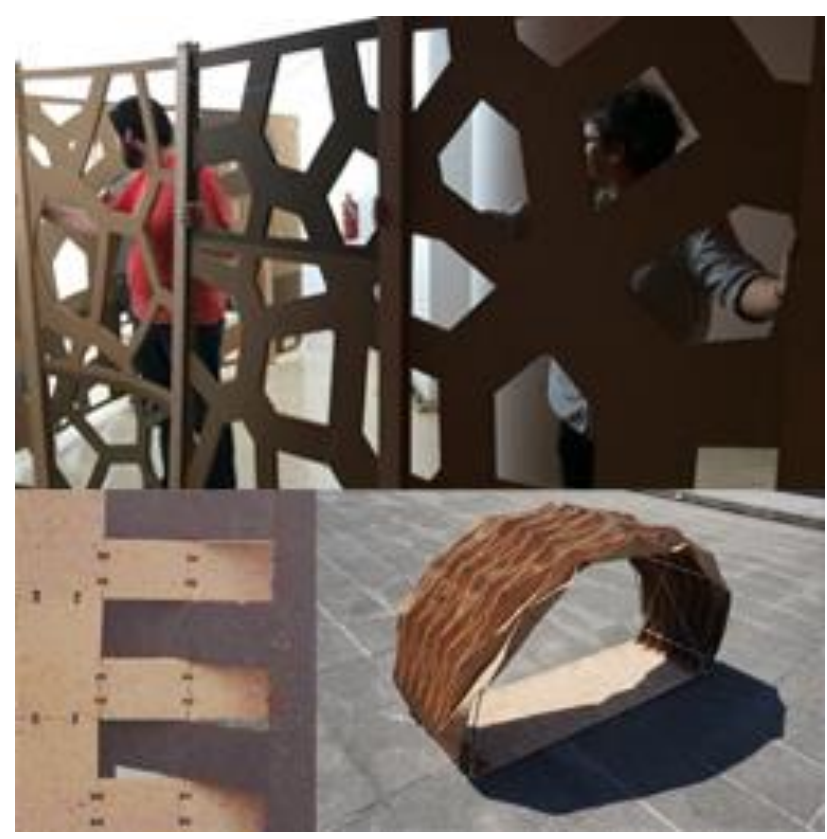

Figure 6: Cork is used as a cladding material (top). Cork used as a self-supporting material (left). Cork used as a membrane (right). Source: Author.

These three examples show the final pieces developed from over 20 examples. In Figure 6 (top), a wooden structure is holding layers of cork composite material, which were parameterized using computer software to create grading openings from opaque to more transparent. A three-dimensional butterfly-joint was designed and cast using a CNC machine. The different butterfly-joints with angles of $30^{\circ}, 45^{\circ}, 60^{\circ}$ and $90^{\circ}$ allowed for multiple possibilities of assemblage. The strength of this highdensity composite cork agglomerated allowed for different types of assemblage using these joints. The system can generate different shapes using only cork materials structure and support (left). A small tent was developed using a cork textile and an origami technique. The folding of the origami creates stiffness to the textile and allows for easy folding of the tent (right).

\section{RESEARCH DISSEMINATION}

Approximately these workshops had around 30 participants per year, from Portugal, other European countries, Brazil, Canada and Japan. Five Portuguese universities and one Canadian university participated in the event. We also had the participation and contribution of well-recognized researchers in cork materials, engineering and biology. The involvement with the industry is crucial for this research. This research showed that it is possible to work at the same time with different cork companies with a large spectrum of materials. On the 27th of May 2016, the Observatorio da Cortiça (Cork Observatory), organized a conference "Cork - News Uses in Architecture", in partnership with the University of Lisbon and Dalhousie University. That conference put together industry, universities, architects and designers, discussing future opportunities for partnerships.

\section{A Facebook page was created in 2014.}

Since then the exhibition has travelled through Portugal. By the end of July 2018 it will be in Portel Municipality.

\section{CONCLUSIONS}

This research is creating greater awareness of the potentialities of cork as a sustainable material and seeks possible new uses of cork materials in architecture. It is an opportunity to replace fossil fuel materials in architecture, with the advantage of investing in our forests and natural habitats.

Cork is a material that is still imbedded in the Mediterranean culture. Further, it may contribute to greater sustainability in the construction business. We have tested, and adapted materials developed for industrial uses into possible architectural uses, hoping that in the future there will be greater application in architecture and eventually will

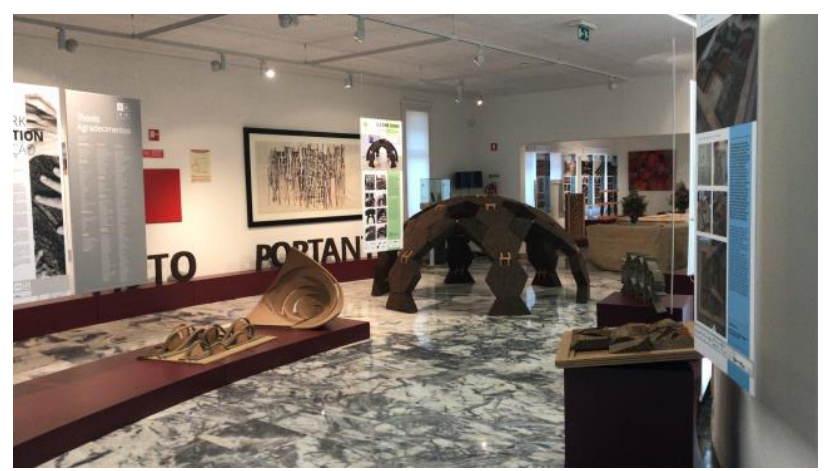

Figure 7: View of the exhibition, at the Observatorio da Cortiça in Coruche, 2018. Source: Author.

contribute to a greater sustainability in the construction, design industries as well as in the cork sector.

The results of these three-year initiatives indicate that there is a clear interest by the different Universities, institutions and Industries to continue to support this research and the work developed in the workshops. It has been demonstrated that it is a wonderful platform to reach out to young generations of future architects and designers about the opportunities to use cork in architecture.

This research explored cork industry wastage, cork recycling and new cork-based materials, which are still in various stages of development with enormous potential for the construction - related industries.

Due to the physical and mechanical properties of the natural cork and cork composite materials, subtractive manufacturing processes are the most suitable, since the additives do not yet have a production scale appropriate to the architecture.

Within subtractive manufacturing processes CNC (Numerically Controlled Computer), the following technologies seems to have greater advantages at the moment to be implemented in architecture products: milling, laser cutting, and jet cutting. 


\section{ACKNOWLEDGMENTS}

This research has been possible through the support of the Faculdade de Arquitectura da Universidade de Lisboa, Architecture School and Planning of Dalhousie University, Curuche Municipality and all the sponsors, researchers and students who share their knowledge and time to envision new uses for Cork in Architecture.

\section{REFERENCES}

Gil, L., 2007 "Cork as a Building Material. Technical Manual". Santa Maria de Lamas: APCOR.

Gil L. 2010. "A cortiça, o ambiente e a sustentabilidade" (in Portuguese). Biol. Soc. 10, 13-15

Gil L. 2011. "Environmental, sustainability and ecological aspects of cork products for building". Sci. Technol. Mater. 23, 87-90

Gil L., Moiteiro C. (2003). “Cork” in Ullmann's Encyclopedia of Chemical Technology", 6th Edn. Germany: Wiley-VCH Verlag

Kieran, S., \& Timberlake, J. (2003). Refabricating architecture. New York: McGraw-Hill. Retrieved from http://www.magisterarq.cl/fileadmin/docs/trayectoria trabajos/ Arquitectura e industria/61 Refabricating Processes MAC ARENABURDILES.pdf
Pereira H., 2007. "Cork: Biology, Production and Uses". Amesterdam: Elsevier: 26-29, 33 -53.

Potes, J. \& Babo, H. 2003. "Montado" an old system in the new millennium" African Journal of Range \& Forage Science, 20 (2): 131-146

Santos, C.O., 2000 (in Portuguese) "O Livro da Cortiça". Ed. Carlos Oliveira Santos/Diglivros. (65-72)

Santos, C. O. \& Amorim, A., 2008, "Clusters United by Nature: the World of Wine and Cork", Amorim Group, 29-32

Muchagato J.; Oliveira Martins A., 2013" Convento of the Capuchos", Parques de Sintra and Scala Arts \& Heritage Publishers,

Pestana, M. e Tinoco, I., 2008 (in Portuguese) "A Indústria e o Comércio da Cortiça em Portugal durante o Século XX", 1-5

Chebao, F. 2011, (in Portuguese) "Cortiça e Arquitetura". Euronatura, 51-81

Varela, P. A., Paio, A., \& Sousa, J. P. (2014). The cork vault pavilion: A Design Research through Practice. In F. Madeo and F. Novi (Ed.), Architectural Research through to Practice: 48th International Conference of the Architectural Science Association (pp. 395-404). Genova: The Architectural Science Association.

[https://www.facebook.com/corkworkshop, accessed on 28/June 2018 16:51]. 